nearly parallel (see p. I40 of the paper above referred to). The ordinate in all these cases is the thermoelectric power.

The special feature here is the period of silence at the neutral point of $\mathrm{N}$ and steel, viz., about $250^{\circ} \mathrm{C}$.

This observation agrees remarkably well with the theory that the initial sound in the case of steel is due to its permanent magnetism ; for, according to Faraday, steel loses its coercitive force about the temperature of boiling almond oil. See also Marshall (Proc. R.S.E., $1871-72$, p. 605). On cooling, owing doubtless to the fact that exposure to a high temperature had softened the steel, which was very hard to begin with, no period of absolute silence appeared, and beats were heard.

It was difficult to distinguish whether the note at $\mathrm{E}$ and $\mathrm{F}$ was or was not due to the singing of the Bunsen flame. The observations, on cooling, exactly corroborated those taken during heating.

It appears to me that these experiments establish that a series of sounds are produced by the passage of a varying current through magnetised iron, nickel, and cobalt, which depend on the fact of their magnetism. They are apparently of the same nature as those observed heretofore in magnetising and demagnetising iron.

I believe that the phenomena above described explain the exceptional power of iron wires of considerable thickness, as sounders in the wire telephone. When the iron wire is very thin it is most likely that the effect obtained with thin wires of ordinary metals predominates, and it is possible that the magnetic effect may in that case be very small. I cannot say, however, that I have settled this point, which clearly involves an experimental difficulty.

At all events I hope the above observations will be of sufficient interest to attract notice to a subject which has not been much studied lately, notwithstanding its important bearings on the theory of the telephone, and what is of more scientific importance still, the theory of magnetism in strongly-magnetic bodies, a department of physics which stands in as much need of additional light as any that I know.

G. Chrystal

\section{INTERNATIONAL METEOROLOGY}

THE International Meteorological Committee appointed by the Congress of Rome (1879), will hold its first meeting at Berne on the 9 th proximo.

The following is the programme of questions to be considered by the Committee :-

r. Report on the action of the Committee since the date of the Congress at Rome.

2. Report of the Polar Conference (Weyprecht's project) held at Hamburg in October, 1879.

3. Proposed Conference for Agricultural Meteorology, summoned for September 6 at Vienna.

4. Proposed comparison of the Standard Instruments of the chief Observatories of Europe.

5. Proposed Catalogue of Meteorological Observations and of Meteorological Works and Memoirs in all languages.

6. Proposed International Tables for the reduction of observations.

7. Proposal for an International Meteorological Dictionary.

8. Report on the Meteorological Organisation of England in 1877, being a Supplement to the Fifth Appendix to the Report of the Roman Congress.

9. Proposal by Capt. Hoffmeyer for an International Telegraphic Service for the North Atlantic.

10. Proposal respecting the exchange of Meteorological Publications by post.

The Circular concerning the meeting, which is issued by Prof. Wild and Mr. Scott, requests all persons wishing to make any communications to the Committee to address them to Mr. Scott, at II6, Victoria Street, during the current month.

A private Conference on the relations of Meteorology to Agriculture and Forestry will be held at Vienna on September 6. The following is the programme of subjects for discussion :-

I. What are the mutual relations of the meteorological elements on vegetation, not only those which are proved to exist, but those which are theoretically supposed to be probable?

2. What observations of meteorological elements are to be particularly attended to, with especial reference to their influence on vegetation?

3. How tar, and in what way, can meteorological observa- tories and stations, without interfering with their other work, include these observations in their sphere of operation?

4. Would it not be useful with a view of establishing special systems of observations for this object, as, for instance, phenological observations, to prepare general instructions ?

5. Can, at the present moment meteorological central offices issue weather forecasts for the use of agriculture, with reasonable prospects of utility, and if this question is answered in the affirmative, how can the service be organised as fully as possible?

Preliminary materials for the answers to these questions will be found in the Reports of Dr. Lorenz and Dr. Bruhns to the Roman Congress on Article 35 of the Programme. These Reports have also been published separately in German, and partially in French in the collection issued by the Central Office at Rome of all Reports presented to the Congress. In the latter volume the Report of M. Denza on the same subject is to be found.

\section{UNIVERSITY AND EDUCATIONAL INTELLIGENCE}

A Town's meeting was held at Liverpool last week for the purpose of hearing a report from the committee appointed a year or two ago as to the progress of a scheme for establishing a University College in Liverpool. The report showed that in spite of bad times a very gratifying readiness had been exhibited on the part of a number of the leading residents of Liverpool to contribute to the necessary funds, several of whom had promised sums of $\mathrm{xo}, 00 \mathrm{l}$. each for the endowment of different chairs. The Earl of Berby had also promised a similar sum, the result being that $80,000 \mathrm{l}$. was already insured. The col. lege is to be upon the broadest basis, being non-sectarian, and offering no disabilities of any kind to intending students. A resolution was moved thanking donors to the fund, pledging the meeting to the furtherance of the scheme, and recommending that the different classes and businesses of the town should form themselves into committees for the purpose of canvassing.

IN reply to a question by Sir J. Lawrence on Monday as to the embarrassed position of the United College of St. Andrews, Sir W. Harcourt stated that the Government would consider the report during the recess, with a view to making some proposal early next session.

A COMMITTEe is to be appointed to inquire as to the existing establishments which are available for intermediate and higher education in Wales.

THE Superior Council of Instruction in France has terminated its second session. The most notable feature has been the introduction of descriptive natural history in the eighth class, that is, in the first step of classical education.

\section{SCIENTIFIC SERIALS}

Annalen der Physik und Chemie, No. 6.-On electric expansion, by $\mathrm{G}$. Quincke.-On the thermal and optical behaviour of gases under the influence of electric discharges, by E. Wiedemann.-On the electro-magnetic rotation of the plane of polarisation of light in gases, by A. Kundt and W. C. Röntgen.-On the theory of inconstant galvanic elements, by F. Exner.-On the specific heat of water, by $\mathrm{A}$. Wiillner.-On the specific heat of mixtures of acetic acid and water, by M. A. von Reiss.-On a changed form of my proof of Maxwell's law of distribution of energy, by $\mathrm{O}$. E. Meyer.-Researches on heat-conduction in liquids (continued), by H. F. Weber.-On anomalous dispersion in glowing sodium-vapour, by A. Kundt.-On a simple method of galvanic calibration of a wire, by V. Stroubal and C. Barus.-Explosive actions by ice, by Ed. Hagenbach.-On the funnel-valve in evacuated tubes, by W. Holtz.

No. 7.-Experiments on stationary vibrations of water, by G. Kirchhoff and G. Hansemann,--On the nature of galvanic polarisation, by W. Beetz.-Key for electric circuits, by the same.-On electric expansion (continued), by G. Quincke.Experiments for Jetermination of an upper limit for the kinetic energy of the electric current, by H. R. Hertz.-On fluorescence, by $\mathrm{E}$. Lommel. - Researches on heat-conduction in liquids, by H. F. Weber.-On the transverse vibrations of a bar of variable cross-section, by $\mathrm{G}$. Kirchhoff, 